ARTICLE

\title{
A reaction mode of carbene-catalysed aryl aldehyde activation and induced phenol $\mathrm{OH}$ functionalization
}

Xingkuan Chen ${ }^{1}$, Hongling Wang ${ }^{2}$, Kazuki Doitomi ${ }^{1,3}$, Chong Yih Ooi ${ }^{1}$, Pengcheng Zheng ${ }^{2}$, Wangsheng Liu ${ }^{4}$, Hao Guo ${ }^{4}$, Song Yang ${ }^{2}$, Bao-An Song ${ }^{2}$, Hajime Hirao ${ }^{1,3} \&$ Yonggui Robin Chi ${ }^{1,2}$

The research in the field of asymmetric carbene organic catalysis has primarily focused on the activation of carbon atoms in non-aromatic scaffolds. Here we report a reaction mode of carbene catalysis that allows for aromatic aldehyde activation and remote oxygen atom functionalization. The addition of a carbene catalyst to the aldehyde moiety of 2-hydroxyl aryl aldehyde eventually enables dearomatization and remote $\mathrm{OH}$ activation. The catalytic process generates a type of carbene-derived intermediate with an oxygen atom as the reactive centre. Inexpensive achiral urea co-catalyst works cooperatively with the carbene catalyst, leading to consistent enhancement of the reaction enantioselectivity. Given the wide presence of aromatic moieties and heteroatoms in natural products and synthetic functional molecules, we expect our reaction mode to significantly expand the power of carbene catalysis in asymmetric chemical synthesis.

\footnotetext{
${ }^{1}$ Division of Chemistry \& Biological Chemistry, School of Physical \& Mathematical Sciences, Nanyang Technological University, Singapore 637371, Singapore. ${ }^{2}$ Laboratory Breeding Base of Green Pesticide and Agricultural Bioengineering, Key Laboratory of Green Pesticide and Agricultural Bioengineering, Ministry of Education, Guizhou University, Huaxi District, Guiyang 550025, China. ${ }^{3}$ Department of Biology and Chemistry, City University of Hong Kong, Tat Chee Avenue, Kowloon Tong, Hong Kong 999078, China. ${ }^{4}$ Department of Chemistry, Fudan University, 220 Handan Road, Shanghai 200433, China. Correspondence and requests for materials should be addressed to H.H. (email: hhirao@cityu.edu.hk) or to Y.R.C. (email: robinchi@ntu.edu.sg).
} 
A romatic moieties are among the most common functional groups in natural products, bioactive molecules and polymeric materials. Thus, selective functionalization of aromatic molecules and their derivatives has received continuous attention in organic synthesis. Currently, the field of aromatic molecule functionalization, such as aromatic $s p^{2}-\mathrm{CH}$ activation and benzylic $s p^{3}-\mathrm{CH}$ activation, is dominated by transition metal catalysis $^{1-3}$. Organic catalyst-enabled activation of aromatic or benzylic carbon as reactive centre has been much less developed. Representative examples in this direction include photoredox/ organocatalytic radical reactions from MacMillan and colleagues ${ }^{4}$ and Melchiorre and colleagues ${ }^{5}$, and amine-mediated reactions via an enamine or iminium intermediate from Melchiorre and colleagues $^{6}$, Jørgensen and colleagues ${ }^{7}$, Chen and colleagues ${ }^{8}$ and $\mathrm{Xu}$ et al. ${ }^{9}$. In the area of $N$-heterocyclic carbene (abbreviated as NHC or carbene in this manuscript) organocatalysis ${ }^{10,11}$, aldehydes $^{12-16}$, esters ${ }^{17-19}$ and ketenes ${ }^{20,21}$ have been widely' employed as substrates. However, nearly all these reactions were focused on using carbon atoms in non-aromatic (and acyclic) molecules as the reactive sites (Fig. 1a). For example, the $\alpha$ and $\beta$ carbons of acyclic $\alpha, \beta$-unsaturated aldehydes ${ }^{22}$ have been widely explored with a large set of asymmetric reactions. In contrast, aromatic aldehydes are only used in benzoin-type reactions. It remains challenging for the stereo-electronic power of the carbene catalyst to go across the conjugated bonds of the aromatic frameworks to induce activation and selective reactions (Fig. 1b). In 2013, we disclosed that the benzylic $s p^{3}-\mathrm{CH}$ of indole-type heteroaryl aldehyde ${ }^{23}$ could be activated via an analogous vinyl enolate intermediate (NHC-bound o-QDMs, Fig. 1b). However, the activation of simple aromatic aldehydes (such as benzaldehyde) without heteroatom incorporated in the aromatic rings remains difficult.

Here we demonstrate that the simple aryl aldehyde could be activated by a carbene catalyst (Fig. 1c). Addition of the carbene catalyst to the aldehyde moiety of 2-hydroxyl benzaldehyde (salicylaldehyde, 1a) eventually leads to acyl azolium intermediate I under an oxidative condition. The electron-withdrawing effect from the acyl azolium moiety, in combination with the electrondonating ability of the $\mathrm{OH}$ group, enables a dearomatization ${ }^{24}$ process that forms azolium-bound ortho-quinone methide intermediate II $(o-\mathrm{QM})$. Ortho-quinone methide is a reactive intermediate broadly used in the synthesis of sophisticated natural products and other functional molecules ${ }^{25,26}$. The oxygen atom in intermediate II behaves as an active site to react with ketone substrate $\mathbf{2 a}$ to afford chiral ketal-like $\mathbf{3 a}$ as the product. The overall process is a carbene-catalysed functionalization of the phenol $\mathrm{OH}$ group via a type of NHCbound $o$-QMs intermediate (II). Notably, in nearly all of the reported reactions, only carbon atoms of the NHC-bound intermediates (Fig. 1a) were explored as the reactive centres $^{27,28}$. The exceptions are NHC-mediated polymerization of lactone $e^{29}$ and Breslow intermediate-induced ring expansion ${ }^{30-32}$. Our present work realizes oxygen atom activation, in which the reactivity of the oxygen atom is modulated by the covalent-bound NHC catalyst in intermediate II. The azolium-bound orthoquinone methides intermediate (II) constitutes a new mode for NHC catalysis. Additionally, we realize a urea/NHC cooperative catalytic process ${ }^{33}$ (III, Fig. 1c), in which an achiral urea co-catalyst significantly and consistently improves the enantioselectivity of the reaction.

\section{Results}

Reaction optimizations. Key results of initial optimization of reaction conditions are summarized in Table 1 . Salicylaldehyde (1a) and trifluoroacetophenone (2a) were chosen as the model substrates to form 1,3-dioxin-4-one (3a). Studies on the solvent effects (see Supplementary Tables 2 and 3 ) found that a mixture of $\mathrm{CH}_{2} \mathrm{Cl}_{2} /$ hexane $(1: 1, \mathrm{v} / \mathrm{v})$ is the optimal choice. Quinone (DQ), first explored by Studer and colleagues in NHC catalysis ${ }^{34}$, is an effective oxidant. Several bases (see Supplementary Table 1) could produce the desired product in such transformations. In the absence of NHC catalyst, product $\mathbf{3 a}$ was not formed. The two starting materials (1a and $\mathbf{2 a}$ ) remained unreacted and could be recovered (entry 1). The search for NHC catalysts found that aminoindanol-derived triazolium precatalyst $\mathbf{C l}$ with an $N$-mesityl substituent (first explored by Bode ${ }^{35}$ ) could mediate the formation of $\mathbf{3 a}$ in $58 \%$ yield and with 63:37 e.r. (entry 2). The reaction yield could be dramatically increased to $97 \%$ when precatalyst C2 with an $\mathrm{N}$-trichlorophenyl substituent (first explored by Rovis ${ }^{36}$ ) was used (entry 3 ). Decreasing the reaction temperature from room temperature to $-10^{\circ} \mathrm{C}$ led to a small but consistent improvement in the e.r. value without affecting the reaction yield (entry 4). Further decreasing the reaction temperature, however, slowed down the reaction without enhancing the enantioselectivity. We then turned to identifying conditions that could improve the reaction enantioselectivity. In our studies on the solvent effects (see Supplementary Table 2), we found that solvents could affect the reaction enantioselectivity. For example, when THF was used as the solvent, the e.r. value of 3a decreased from 73:27 to 52:48 (entry 4 versus 5). These results suggest that non-covalent interaction is likely to play an important role in controlling the enantioselectivity of our reactions. We thus examined non-covalent organic catalysts and found that using achiral thiourea ${ }^{37-41} \mathbf{A 1}$ as a co-catalyst could improve the e.r. values of 3a from 73:27 to 85:15 (entry 6 versus 4). Increasing the amount of A1 led to a lower yield of $\mathbf{3 a}$ with little benefit to the enantioselectivity (entry 7). Further studies found that both thiourea and urea ${ }^{42}$ co-catalysts can improve the enantioselectivity (entries 8 and 9, and see Supplementary Table 4). We finally found that using asymmetric urea A3 could lead to 3 a in $99 \%$ yield and with 94:6 e.r. (entry 9). The loading of the NHC catalyst (C2) could be decreased to $5 \mathrm{~mol} \%$, without affecting the reaction yield and e.r. (entry 11). The urea co-catalyst likely forms hydrogenbonding interactions with the ketone substrate (for example, 2a) and/or intermediate II (Fig. 1c) to improve the reaction enantioselectivity. The hydrogen-bonding interactions are sensitive to solvents. For example, switching the solvent from $\mathrm{CH}_{2} \mathrm{Cl}_{2}$ /hexane to THF led to a dramatic drop in enantioselectivity (entries 10 versus 11 ).

Substrate scope with 2-hydroxyl aryl aldehydes. With an acceptable reaction condition in hand (Table 1 , entry 11), the generality of the reaction was then explored. First, we studied the scope of the 2-hydroxyl aryl aldehydes (Table 2). With trifluoroacetophenone $\mathbf{2 a}$ as a model electrophile, different substituents and substitution patterns on the phenyl ring were examined. Electron-releasing substituents such as alkyl (3b, 3d and $\mathbf{3 k}$ ) and alkoxyl (3c, 3g and $\mathbf{3 j}$ ) units on the phenyl ring of the aldehyde substrates were well tolerated. Electronwithdrawing groups such as halogen atoms (3e, $\mathbf{3 f}$ and $\mathbf{3 h}$ ) and carboxylic ester units (3i) could also be placed on the phenyl ring of the aldehyde substrates. It is worth noting that the steric effect of substituents in different positions on the phenyl ring does not affect the results, as seen for the substrates with 3- and 6- substituents on the 2-hydroxyl aryl aldehydes, but these substitution patterns both led to very good yields and e.r. (3j, 3k and $\mathbf{3} \mathbf{l}$ ). Product 3m bearing a sesamol moiety (3,4-methylenedioxyphenol) could also be made by our method. The benzene ring of la could be extended to other aromatic frameworks, such as 
<smiles>[R]C/C=C(/[NH-])[O-]</smiles><smiles></smiles>

Enolate<smiles>[R]C(=[V])/C=C(/[O-])[N-]C</smiles>

Vinylogous enolate

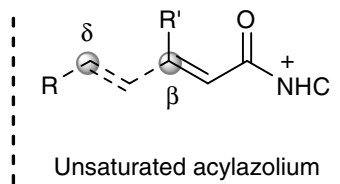

b Hetero aromatic aldehyde benzylic $\mathrm{C}-\mathrm{H}$ activation (our earlier work)<smiles>O=Cc1ccccc1O</smiles>

Challenging (remains unsolved)<smiles>O=Cc1c(O)n(C(=O)O)c2ccccc12</smiles>

Indole-type aromatic aldehyde (our earlier work)

C Simple aryl aldehyde activation and $\mathrm{O}-\mathrm{H}$ bond functionalization (this work)<smiles>N#CC1CCCCC1O</smiles>

1a<smiles>C[NH2+]C([O-])=C1C=CC=CC1=O</smiles>

O-QMs<smiles>CCOC(=O)c1cccc2c1OC(c1ccccc1)(c1ccccc1)C(F)(F)O2</smiles>

$99 \%$ yield, $94: 6$ e.r. (w/o urea, $73: 27$ e.r.)

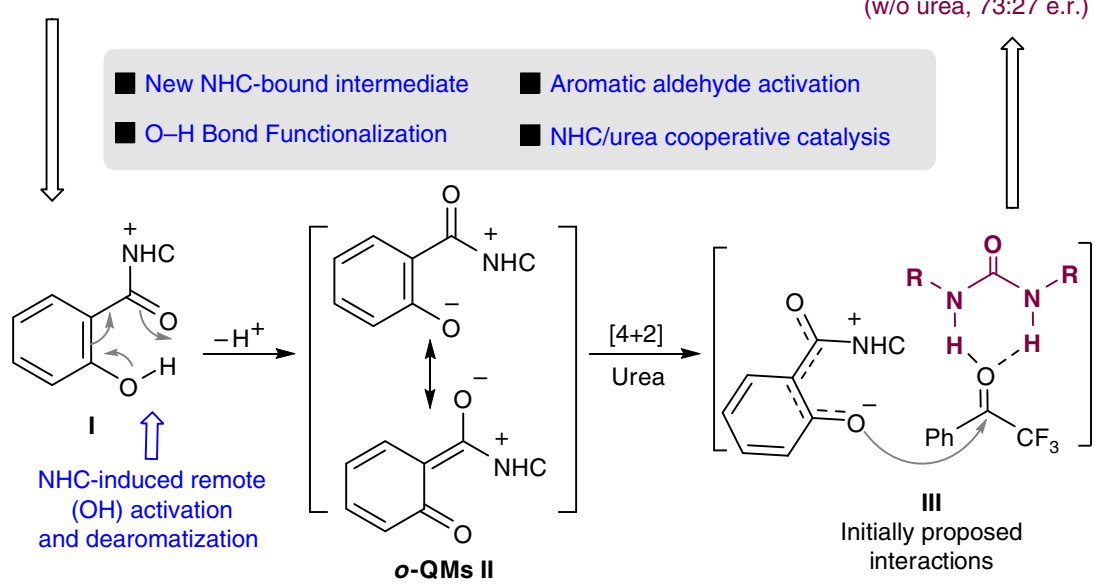

Figure 1 | Activation modes in carbene organic catalysis. (a) Previous studies mainly dealt with carbon atom activation for acyclic non-aromatic carbonyl compounds. (b) Our earlier studies realized indole-type heteroaryl aldehyde benzylic carbon activation. (c) Addition of carbene catalyst eventually leads to simple phenyl aldehyde activation which induces phenol oxygen atom functionalization via a new azolium-bound intermediate (II).

naphthyl units (3n-3p). Additionally, steric influence has little effect on the reaction outcomes for all the three naphthaldehyde substrates $(\mathbf{3 n}-\mathbf{3} \mathbf{p})$. Notably, in all cases, the reactions were highly efficient, and the products were obtained in excellent yields. The two starting materials were used with nearly a 1:1 ratio.

Substrate scope with trifluoromethyl ketones. We next examined the reactions of trifluoromethyl ketone substrates $\mathbf{2}$ in our standard condition (Table 3). Here we chose 5-methylsalicyladehyde (1b) as a model aldehyde substrate because it is easier to handle than $\mathbf{1 a}$, as $\mathbf{1 b}$ is a solid at room temperature and stable toward air-oxidation. Different substituents and substitution patterns on the phenyl ring of the ketone substrates were all tolerated (3b and $\mathbf{3 q}-\mathbf{3} \mathbf{x}$ ). Electron-donating groups such as methyl (3q), methoxy (3r) and $N, N$-dimethyl amino (3s) groups on the phenyl para-position were all tolerated, giving the corresponding products with excellent values of yield and e.r. Electronwithdrawing substituents on the phenyl meta- or para- position (3t, 3x) had little effect on the yields and selectivities. The phenyl substituent of ketone $\mathbf{2 a}$ could be replaced by a heteroaryl substituent (3y). Alkyl substituted trifluoromethyl ketones are typically challenging substrates when used as electrophiles because of the ketone/enol isomerization. These substrates could be used in our reactions as well $(\mathbf{3 z}, \mathbf{3 z a})$, albeit with a small to moderate drop in the yield and e.r. values.

DFT studies on NHC-bound intermediate II. DFT calculations were used to assess the nature of $o-\mathrm{QM}$ in intermediate II. The computational details are provided in the Supplementary Figs 56-65. Six conformers of II were obtained from DFT calculations. The optimized structure of the most stable conformer of intermediate II (II-1), which can later react with ketone 2a, is shown in Fig. 2a. Other less stable structures are shown in the Supplementary Information. We also calculated Mulliken atomic charges for II-1 and found that the $\mathrm{O} 1$ and $\mathrm{O} 2$ atoms have partial negative charges of -0.33 and -0.47 , respectively (Fig. 2b); the magnitudes of these values are significantly smaller than 1. These fractional charges imply that II-1 cannot be 


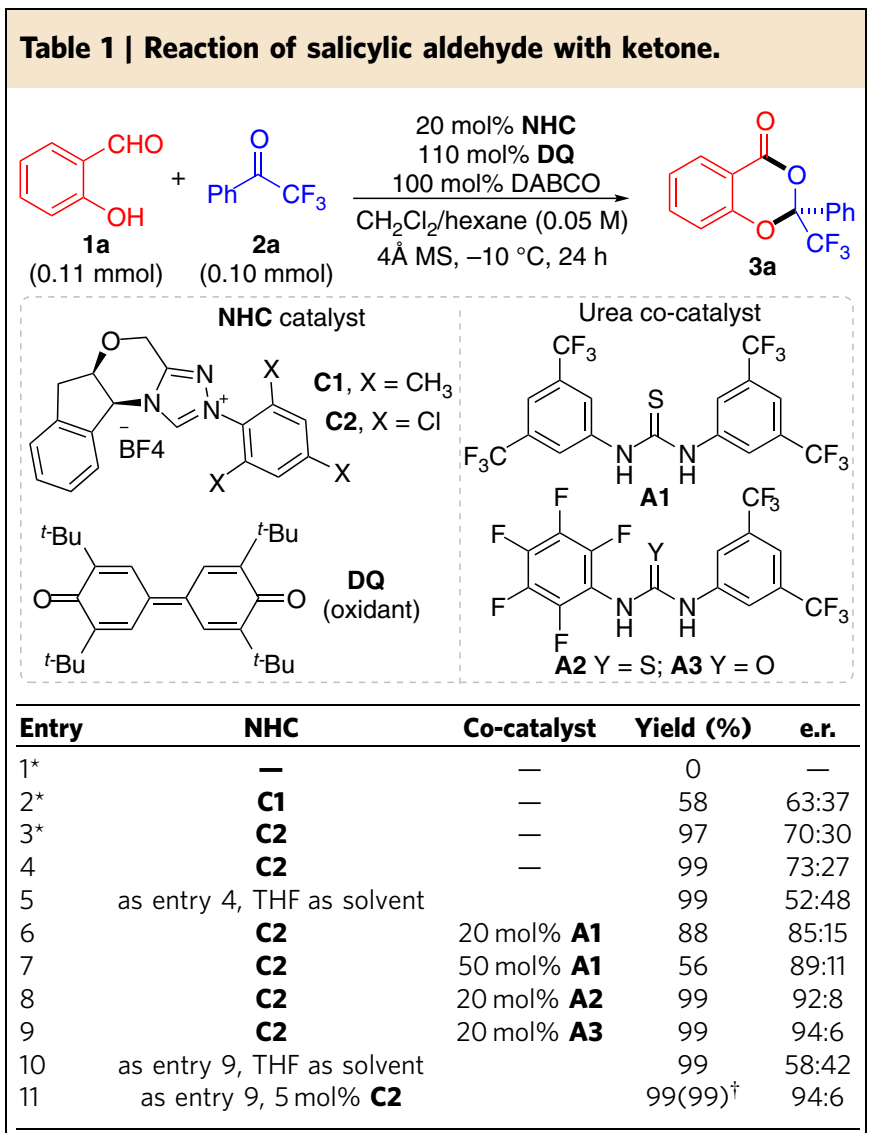

The yield of 3a was estimated via ${ }^{1} \mathrm{H}$ NMR analysis with an internal standard. The e.r. of 3a was determined via chiral-phase high-performance liquid chromatography (HPLC).

determined via chiral-phase high-performance liquid
${ }^{*}$ Reactions were carried out at room temperature.

†lsolated yield after $\mathrm{SiO}_{2}$ chromatography.

described as either of the two extreme resonance structures depicted in Fig. 2b; instead, the real state of $o$-QM should lie somewhere in between.

DFT studies on the mechanisms of $[4+2]$ annulation. To gain mechanistic insights, DFT calculations were performed for the reaction between intermediate II and ketone substrate $2 \mathbf{a}$ in the presence or absence of a urea co-catalyst, taking into account the solvent effect of DCM (see the Supplementary Tables 6-11 for details). The calculations without urea suggest that NHC-bound intermediate II can react with $\mathbf{2 a}$ in a $[4+2]$ mechanism (Fig. 1c) to afford a ketal-like product, without having very high barriers, thus supporting the hypothesis regarding the involvement of $o$ QM in the reaction. The four conformers (II-1, II-2, II-3 and II4) of intermediate II in Supplementary Fig. 59 can react with 2a, giving rise to several possible reaction pathways (16 pathways in total). DFT calculations without urea showed that this reaction consists of two steps: (1) a ring-annulation step and (2) an NHC dissociation step, and that step 2 should be the ratedetermining step (see the Supplementary Information). On the basis of this result, we performed further calculations with co-catalyst A3.

The lowest-energy transition state for the rate-determining step on Path 1-A (A3-TS2 ${ }_{1-\mathrm{A}}$ ) with urea A3 is connected to the major product. In this transition state, unlike our initial guess (Fig. 1c), urea A3 forms hydrogen bonds preferentially with the carbonyl oxygen atom of the $o$-QM moiety (Fig. 2c), rather than with the trifluoromethyl ketone substrate (Fig. 1c). A3-TS2 $2_{1-\mathrm{A}}$ has attractive $\pi-\pi$ stacking between the pentafluorophenyl group of A3 and the indane moiety of the catalyst (Fig. 2d). Such $\pi-\pi$ stacking is also observed in A3-TS2 $2_{1-\mathrm{A}-m i n o r}$, but not in the other A3-TS2's. The somewhat greater stability of A3-TS2 $2_{1-\mathrm{A}}$ compared with A3-TS2 1 -A-minor is attributed to the attractive dispersion interactions between the urea moiety and the phenyl group from ketone (Fig. 2e), which are prominent only in A3-TS2 $2_{1-\mathrm{A}}$. Our calculations therefore highlight the importance of dispersion interactions in determining the enantioselectivity.

Application of the $[4+2]$ annulation products. Our reaction is amenable for large-scale synthesis (Fig. 3a). Notably, in the gram scale synthesis, the use of $1 \mathrm{~mol} \%$ NHC precatalyst was sufficient to produce $3 \mathbf{b}(1.5 \mathrm{~g})$ in $98 \%$ yield and with $96: 4$ e.r. Additionally, the organic oxidant (DQ) could be used in catalytic amount by using inexpensive $\mathrm{MnO}_{2}$ as a terminal oxidant ${ }^{43}$ (Fig. 3b).

The products of our catalytic reactions contain a benzo[1,3]dioxin scaffold. This chiral benzo[1,3]dioxin unit itself and its closely related structures are widely found in natural products and bioactive synthetic molecules. Examples of such molecules include natural product Epicocconigrone $\mathrm{A}$ with anticancer activities $^{44}$ and Efavirenz, commercially used as an HIV reverse transcriptase inhibitor ${ }^{45}$. Our laboratories are interested in the antiviral and antibacterial activities of these compounds for agricultural use ${ }^{46-48}$. Therefore, we then evaluated the in vitro bioactivities of our products against several types of bacteria and fungi that can cause plant infections (Table 4). The commercially available and commonly applied bactericide Kresoxim-methyl was used as the positive control, and dimethyl sulfoxide was used as the negative control. Preliminary studies found that several of our compounds showed significant activities against Eggplant Verticillium, Phytophthora infestans and Fusarium oxysporum. For example, compound 31 showed 25-38\% inhibition rates against the above three fungi at a concentration of $50 \mu \mathrm{g} \mathrm{ml}^{-1}$.

\section{Discussion}

In short, we have developed a reaction mode of carbene-catalysed activation of aryl aldehydes. Addition of the carbene catalyst to the aldehyde moiety eventually leads to remote phenol $\mathrm{OH}$ activation and dearomatization. The catalytic reaction involves an NHC-bound intermediate ( $o$-QMs) with the oxygen atom acting as the reactive centre. A hydrogen-bond donating co-catalyst (urea or thiourea) works cooperatively with the NHC catalyst, resulting in significant and consistent enhancement of the reaction enantioselectivity. Our method is amenable for largescale enantioselective synthesis with relatively low loading of the NHC catalyst. Preliminary studies on the bioactivities of our compounds identified a few leads with antifungal activities. We expect our study to encourage further exploration on new reaction modes and alternative intermediates with $\mathrm{NHC}$ organic catalysis. Our findings of $\mathrm{NHC} /$ urea cooperative catalysis will provide some possibilities in controlling challenging stereoselectivities, for example, in remote group functionalizations.

\section{Methods}

General strategy of [4+2] annulations. To a $10 \mathrm{ml}$ flame-dry Schlenk reaction tube equipped with a magnetic stir bar, chiral NHC pre-catalyst C2 $(0.005 \mathrm{mmol}$, $5 \mathrm{~mol} \%, 2.4 \mathrm{mg}$ ), urea A3 (0.02 mmol, $20 \mathrm{~mol} \%, 8.76 \mathrm{mg})$, DABCO (0.1 mmol, $100 \mathrm{~mol} \%, 11.2 \mathrm{mg})$, oxidant DQ $(0.11 \mathrm{mmol}, 110 \mathrm{~mol} \%, 45 \mathrm{mg})$, aldehyde $(0.11 \mathrm{mmol})$ and $4 \AA$ molecular sieves were added. The Schlenk tube was sealed with a septum, evacuated and refilled with nitrogen ( 3 cycles). Solvent $\left(\mathrm{CH}_{2} \mathrm{Cl}_{2} /\right.$ hexane $\left.=1: 1,2.0 \mathrm{ml}\right)$ and trifluoromethyl ketone $2(0.1 \mathrm{mmol})$ were then added via syringe. The reaction mixture was allowed to stir for $24 \mathrm{~h}$ at $-10^{\circ} \mathrm{C}$. After completion of the reaction, monitored by a TLC plate, the reaction mixture was concentrated under reduced pressure, and the residue was subjected to column chromatography or TLC plate directly using hexane/EtOAc as eluent to afford the desired product 3 . For ${ }^{1} \mathrm{H},{ }^{13} \mathrm{C},{ }^{19} \mathrm{~F}$ NMR and high-performance liquid chromatography spectra of compounds in this manuscript, see Supplementary Figs 1-54. 
Table 2 | Examples of 2-hydroxyl aryl aldehyde substrates.

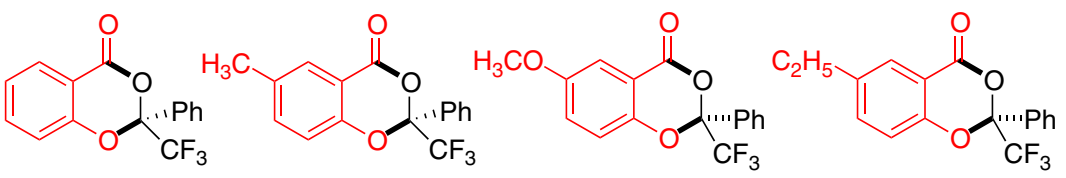

3a: $99 \%, 94: 6$ e.r.

3b: $99 \%, 96: 4$ e.r.

3c: $98 \%, 96: 4$ e.r.

3d: 95\%, 96:4 e.r.<smiles></smiles>

3e: $93 \%, 91: 9$ e.r.

3f: $83 \%, 92: 8$ e.r.

3g: $98 \%, 94: 6$ e.r.

3h: $87 \%, 91: 9$ e.r.<smiles>COC(=O)c1ccc2c(c1)OC(c1ccccc1)(c1ccccc1)OC2=O</smiles><smiles>CCOc1cccc2c1OC(c1ccccc1)(C(F)(F)F)OC2=O</smiles>

3i: $93 \%, 90: 10$ e.r.

3j: $87 \%, 97: 3$ e.r.<smiles>Cc1cccc2c1OC(c1ccccc1)(C(F)(F)F)OC2=O</smiles><smiles>Cc1cc(C)c2c(c1)OC(c1ccccc1)(C(F)(F)F)OC2=O</smiles><smiles>O=C1OC(c2ccccc2)(c2ccccc2)Oc2cc3c(cc21)OCO3</smiles><smiles>O=C1OC(c2ccccc2)(c2ccccc2)Oc2ccc3ccccc3c21</smiles>

3m: 91\%, 97:3 e.r.

3n: $92 \%, 98: 2$ e.r.

3k: $86 \%, 93: 7$ e.r.

31: $84 \%, 98: 2$ e.r.<smiles>O=C1OC(c2ccccc2)(c2ccccc2)Oc2c1ccc1ccccc21</smiles>

3o: $94 \%, 95: 5$ e.r.<smiles>O=C1OC(c2ccccc2)(c2ccccc2)C(F)(F)Oc2cc3ccccc3cc21</smiles>

3p: $87 \%, 94: 6$ e.r.

Conditions as Table 1, entry 11. Yields are the isolated yield after $\mathrm{SiO}_{2}$ column chromatography. The e.r. was determined via chiral-phase HPLC analysis. Supplementary crystallographic data for $\mathbf{3 h}$ can be found in CCDC 1486140

Table 3 | Scope of trifluoromethyl ketones.<smiles>Cc1ccc2c(c1)C(=O)OC(c1ccccc1)(c1ccccc1)O2</smiles>

3b: $99 \%, 96: 4$ e.r.<smiles>Cc1ccc2c(c1)C(=O)OCO2</smiles>

3q: $99 \%, 98: 2$ e.r.<smiles>CCCCC</smiles>

3r: 99\%, 98:2 e.r.<smiles>COc1ccc([C@]2(C(F)(F)F)OC(=O)c3ccccc3O2)cc1</smiles><smiles>Cc1ccc([C@]2(C(F)(F)F)OC(=O)c3cc(C)ccc3O2)cc1</smiles>

3t: $98 \%, 97: 3$ e.r. $\mathrm{CF}_{3}$<smiles>Cc1ccc2c(c1)C(=O)O[C@](c1ccc(F)cc1)(C(F)(F)F)OC2=O</smiles>

3u: $99 \%, 96: 4$ e.r.<smiles>Cc1ccc([C@@]2(C(F)(F)F)OC(=O)c3cc(C)ccc3O2)cc1</smiles>

3v: $99 \%, 95: 5$ e.r. B<smiles>Cc1ccc2c(c1)C(=O)O[C@@](c1cccc(Br)c1)(C(F)(F)F)O2</smiles>

3w: 96\%, 93:7 e.r.<smiles>Cc1ccc2c(c1)C(=O)OC(c1cccc(C(F)(F)F)c1)(C(F)(F)F)O2</smiles>

3x: $94 \%, 96: 4$ e.r.<smiles>Cc1ccc2c(c1)C(=O)O[C@](c1cccs1)(C(F)(F)F)O2</smiles>

3y: 75\%, 89:11 e.r.<smiles>Cc1ccc2c(c1)C(=O)O[C@](Cc1ccccc1)(C(F)(F)F)O2</smiles>

3z: $58 \%, 80: 20$ e.r. $64 \%, 90: 10$ e.r.<smiles>CC[C@]1(C(F)(F)F)OC(=O)c2cc(C)ccc2O1</smiles>

3za: $85 \%, 80: 20$ e.r. $81 \%, 82: 18$ e.r.

Conditions as Table 1, entry 11. Yields are the isolated yields after $\mathrm{SiO}_{2}$ column chromatography. The e.r. was determined via chiral-phase $\mathrm{HPLC}$ analysis.

*Replacing $20 \mathrm{~mol} \%$ A3 to $20 \mathrm{~mol} \%$ A1

Data availability. The X-ray crystallographic coordinates for structures reported in this article have been deposited at the Cambridge Crystallographic Data Centre (3h: CCDC 1486140). These data could be obtained free of charge from The
Cambridge Crystallographic Data Centre via www.ccdc.cam.ac.uk/data_request/cif. For XYZ coordinates of optimized structures in DFT studies on the mechanism, see Supplementary Data 1. 
a

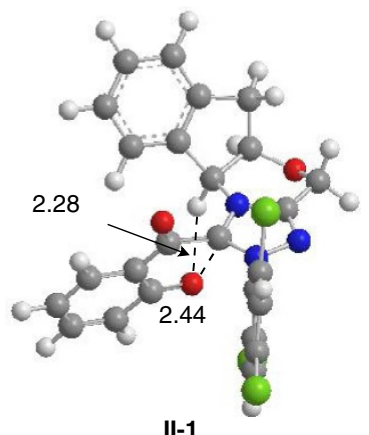

b
$\vdots$
$\vdots$
$\vdots$
$\vdots$
$\vdots$
$\vdots$<smiles>C[NH2+]C(O)=C1C=CC=CC1=O</smiles>

C

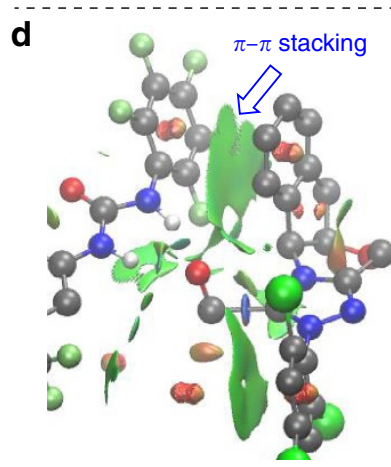

e Atteractive interactions

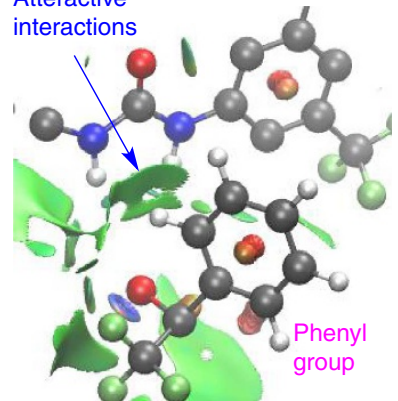

A3-TS2 ${ }_{1-\mathrm{A}}\left(0.0 \mathrm{kcal} \mathrm{mol}{ }^{-1}\right)$

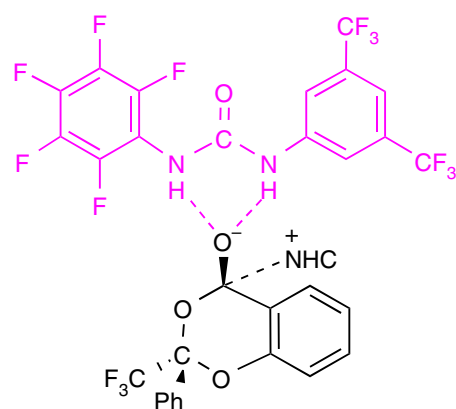

$\mathrm{F}_{3} \mathrm{C}$

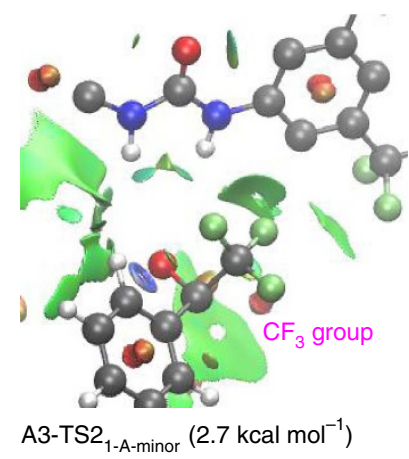

Figure 2 | DFT studies of intermediate II and the roles of urea co-catalyst. (a) Structure of II and key interatomic distances (in $\AA$ ). (b) Resonance structures of II. (c) Schematic drawing of A3-TS2 1 -A. (d) NCI plot for A3-TS2 1-A. Green surfaces represent attractive interactions. Some atoms are omitted for clarity. (e) NCl plots for A3-TS2 $1-\mathrm{A}$ and A3-TS2 1 -A-minor Relative free energies ( $\mathrm{kcal} \mathrm{mol}^{-1}$ ) are with respect to A3-TS2 1 -A.

a<smiles>Cc1ccc(O)c(C=O)c1</smiles>

$1 \mathrm{~b}$

$5.1 \mathrm{mmol}$<smiles>O=C(F)c1ccccc1</smiles>

2a

$5 \mathrm{mmol}$

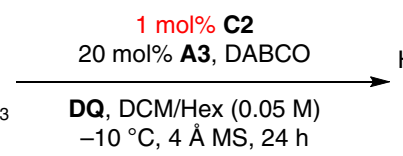

$-10{ }^{\circ} \mathrm{C}, 4 \AA \mathrm{MS}, 24 \mathrm{~h}$<smiles>Cc1ccc2c(c1)C(=O)OC(c1ccccc1)(c1ccccc1)C2(F)C(F)(F)F</smiles>

3b, $1.5 \mathrm{~g}$

98\%, $96: 4$ e.r.

b<smiles>Cc1ccc(O)c(C=O)c1</smiles>

1b

$0.11 \mathrm{mmo}$

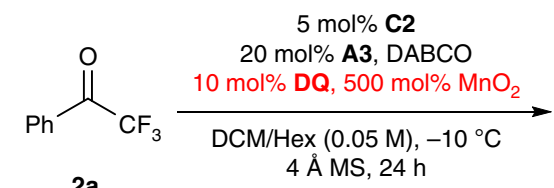

2a

$0.10 \mathrm{mmol}$<smiles>Cc1ccc2c(c1)C(=O)OC(c1ccccc1)(c1ccccc1)C2(F)C(F)(F)F</smiles>

3b

95\%, 95:5 e.r.

Figure 3 | Scalable and practical synthesis. (a) Gram scale synthesis with $1 \mathrm{~mol} \% \mathrm{NHC}$ loading. (b) Reaction using $\mathrm{MnO}_{2}$ as terminal oxidant.

\section{Table 4 | The antifungal activity of our products.}

\section{Sample}

\section{$3 c$}

$3 b$

3i

3)

Positive control

Negative control
Inhibition rate (\%)

Phytophthora infestans

$26.47 \pm 2.45$
$16.98 \pm 6.26$
$10.49 \pm 0.93$
$\mathbf{3 8 . 5 8} \pm \mathbf{0 . 5 9}$
$84.00 \pm 3.59$

0
Fusarium oxysporum

$\mathbf{2 6 . 7 1} \pm \mathbf{2 . 1 8}$

$11.50 \pm 2.75$

$4.71 \pm 1.06$

$25.65 \pm 0.61$

$69.61 \pm 2.54$

Inhibitory effects of compounds at a concentration of $50 \mu \mathrm{g} \mathrm{ml}^{-1}$. Each data is the average of three replicates. Kresoxim-methyl was used as the positive control, Dimethyl sulfoxide was used as negative control. 


\section{References}

1. Wencel-Delord, J. \& Glorius, F. C-H bond activation enables the rapid construction and late-stage diversification of functional molecules. Nat. Chem. 5, 369-375 (2013)

2. Hartwig, J. F. Evolution of $\mathrm{C}-\mathrm{H}$ bond functionalization from methane to methodology. J. Am. Chem. Soc. 138, 2-24 (2016).

3. Zhang, F. L., Hong, K., Li, T. J., Park, H. \& Yu, J. Q. Functionalization of $\mathrm{C}\left(\mathrm{sp}^{3}\right)-\mathrm{H}$ bonds using a transient directing group. Science 351, 252-256 (2016).

4. Qvortrup, K., Rankic, D. A. \& MacMillan, D. W. C. A general strategy for organocatalytic activation of $\mathrm{C}-\mathrm{H}$ bonds via photoredox catalysis: direct arylation of benzylic ethers. J. Am. Chem. Soc. 136, 626-629 (2014)

5. Dell'Amico, L., Vega-Peñaloza, A., Cuadros, S. \& Melchiorre, P. Enantioselective organocatalytic Diels-Alder trapping of photochemically generated hydroxy-o-quinodimethanes. Angew. Chem. Int. Ed. 55, 3313-3317 (2016).

6. Liu, Y., Nappi, M., Arceo, E., Vera, S. \& Melchiorre, P. Asymmetric catalysis of Diels-Alder reactions with in situ generated heterocyclic orthoquinodimethanes. J. Am. Chem. Soc. 133, 15212-15218 (2011)

7. Jiang, H., Rodríguez-Escrich, C., Johansen, T. K., Davis, R. L. \& Jørgensen, K. A. Organocatalytic activation of polycyclic aromatic compounds for asymmetric Diels-Alder reactions. Angew. Chem. Int. Ed. 51, 10271-10274 (2012).

8. Li, J. L., Yue, C. Z., Chen, P. Q., Xiao, Y. C. \& Chen, Y. C. Remote enantioselective Friedel-Crafts alkylations of furans through HOMO activation. Angew.Chem.Int.Ed. 53, 5449-5452 (2014).

9. $\mathrm{Xu}, \mathrm{D}$. et al. A novel enantioselective catalytic tandem oxa-Michael-Henry reaction: one-pot organocatalytic asymmetric synthesis of 3-nitro-2Hchromenes. Adv. Synth. Catal. 350, 2610-2616 (2008).

10. De Sarkar, S., Biswas, A., Samanta, R. C. \& Studer, A. Catalysis with $\mathrm{N}$-heterocyclic carbenes under oxidative conditions. Chem. Eur. J. 19, 4664-4678 (2013).

11. Flanigan, D. M., Romanov-Michailidis, F., White, N. A. \& Rovis, T. Organocatalytic reactions enabled by N-heterocyclic carbenes. Chem. Rev. 115, 9307-9387 (2015).

12. Breslow, R. On the mechanism of thiamine action. IV.1 evidence from studies on model systems. J. Am. Chem. Soc. 80, 3719-3727 (1958).

13. Stetter, H. \& Kuhlmann, H. Addition of aliphatic aldehydes to activated double bonds. Angew. Chem. Int. Ed. 13, 539-539 (1974).

14. Sohn, S. S., Rosen, E. L. \& Bode, J. W. N-heterocyclic carbene-catalyzed generation of homoenolates: $\gamma$-butyrolactones by direct annulations of enals and aldehydes. J. Am. Chem. Soc. 126, 14370-14371 (2004).

15. Burstein, C. \& Glorius, F. Conjugate umpolung of $\alpha, \beta$-unsaturated aldehydes for the synthesis of $\gamma$-butyrolactones. Angew. Chem. Int. Ed. 43, 6205-6208 (2004).

16. Mo, J., Chen, X. \& Chi, Y. R. Oxidative $\gamma$-addition of enals to trifluoromethyl ketones: enantioselectivity control via Lewis acid/N-heterocyclic carbene cooperative catalysis. J. Am. Chem. Soc. 134, 8810-8813 (2012).

17. Hao, L. et al. Enantioselective activation of stable carboxylic esters as enolate equivalents via N-heterocyclic carbene catalysts. Org. Lett. 14, 2154-2157 (2012).

18. Fu, Z., Xu, J., Zhu, T., Leong, W. W. \& Chi, Y. R. $\beta$-Carbon activation of saturated carboxylic esters through $\mathrm{N}$-heterocyclic carbene organocatalysis. Nat. Chem. 5, 835-839 (2013).

19. Ryan, S. J., Candish, L. \& Lupton, D. W. N-heterocyclic carbene-catalyzed generation of $\alpha, \beta$-unsaturated acyl imidazoliums: synthesis of dihydropyranones by their reaction with enolates. J. Am. Chem. Soc. 131, 14176-14177 (2009).

20. Lv, H., Zhang, Y., Huang, X. \& Ye, S. Asymmetric dimerization of disubstituted ketenes catalyzed by N-heterocyclic carbenes. Adv. Synth. Catal. 350, 2715-2718 (2008)

21. Duguet, N., Campbell, C. D., Slawin, A. M. Z. \& Smith, A. D. N-heterocyclic carbene catalysed $\beta$-lactam synthesis. Org. Biomol. Chem. 6, 1108-1113 (2008).

22. Nair, V. et al. Employing homoenolates generated by NHC catalysis in carboncarbon bond-forming reactions: state of the art. Chem. Soc. Rev. 40, 5336-5346 (2011)

23. Chen, X., Yang, S., Song, B.-A. \& Chi, Y. R. Organocatalytic $\alpha$-branched $\mathrm{Sp}^{3}-\mathrm{CH}$ functionalization of indole aryl aldehydes to react with ketones. Angew. Chem. Int. Ed. 52, 11134-11137 (2013).

24. Zhuo, C., Zhang, W. \& You, S.-L. Catalytic asymmetric dearomatization reactions. Angew. Chem. Int. Ed. 51, 12662-12686 (2012).

25. Pathak, T. P. \& Sigman, M. S. Applications of ortho-quinone methide intermediates in catalysis and asymmetric synthesis. J. Org. Chem. 76, 9210-9215 (2011)

26. Willis, N. J. \& Bray, C. D. Ortho-Quinone methides in natural product synthesis. Chem. Eur. J. 18, 9160-9173 (2012).

27. Enders, D., Niemeier, O. \& Henseler, A. Organocatalysis by N-heterocyclic carbenes. Chem. Rev. 107, 5606-5655 (2007).

28. Mahatthananchai, J. \& Bode, J. W. On the mechanism of N-heterocyclic carbene-catalyzed reactions involving acyl azoliums. Acc. Chem. Res. 47, 696-707 (2014)
29. Hedrick, J. L. et al. In situ generation of carbenes: a general and versatile platform for organocatalytic living polymerization. J. Am. Chem. Soc. 125, 3046-3056 (2003).

30. Li, G., Li, Y., Dai, L. \& You, S.-L. N-heterocyclic carbene catalyzed ring expansion of 4-formyl-lactams: synthesis of succinimide derivatives. Org. Lett. 9, 3519-3521 (2007).

31. Wang, L., Thai, K. \& Gravel, M. NHC-catalyzed ring expansion of oxacycloalkane-2-carboxaldehydes: A versatile synthesis of lactones. Org. Lett. 11, 891-893 (2009).

32. She, X. et al. N-Heterocyclic carbene-catalyzed cascade epoxide-opening and lactonization reaction for the synthesis of dihydropyrone derivatives. Org. Biomol. Chem. 9, 5948-5950 (2011).

33. Cohen, D. T. \& Scheidt, K. A. Cooperative Lewis acid/N-heterocyclic carbene catalysis. Chem. Sci. 3, 53-57 (2012).

34. Sarkar, S. D. \& Studer, A. NHC-catalyzed Michael addition to $\alpha, \beta$-unsaturated aldehydes by redox activation. Angew. Chem. Int. Ed. 49, 9266-9269 (2010).

35. He, M., Struble, J. R. \& Bode, J. W. Highly enantioselective azadiene Diels-Alder reactions catalyzed by chiral N-heterocyclic carbenes. J. Am. Chem. Soc. 128, 8418-8420 (2006).

36. Lathrop, S. P. \& Rovis, T. A photoisomerization-coupled asymmetric Stetter reaction: application to the total synthesis of three diastereomers of ( - ) Cephalimysin A. Chem. Sci. 4, 1668-1673 (2013).

37. Doyle, A. G. \& Jacobsen, E. N. Small-molecule H-bond donors in asymmetric catalysis. Chem. Rev. 107, 5713-5743 (2007).

38. Jin, Z., Xu, J., Yang, S., Song, B.-A. \& Chi, Y. R. Enantioselective sulfonation of enones with sulfonylimine via cooperative $\mathrm{NHC} /$ thiourea/tertiary amine multicatalysis. Angew. Chem. Int. Ed. 52, 12354-12358 (2013).

39. Mattson, A. E., Zuhl, A. M., Reynolds, T. E. \& Scheidt, K. A. Direct nucleophilic acylation of nitroalkenes promoted by a fluoride anion/ thiourea combination. J. Am. Chem. Soc. 128, 4932-4933 (2006).

40. Youn, S. W., Song, H. S. \& Park, J. H. Asymmetric domino multicatalysis for the synthesis of 3-substituted phthalides: cinchonine/NHC cooperative system. Org. Lett. 16, 1028-1031 (2014).

41. Wang, M. H., Cohen, D. T., Schwamb, C. B., Mishra, R. K. \& Scheidt, K. A. Enantioselective $\beta$-protonation by a cooperative catalysis strategy. J. Am. Chem. Soc. 137, 5891-5894 (2015).

42. Xu, H., Zhang, H. \& Jacobsen, E. N. Chiral sulfinamidourea/strong Brønsted acid co-catalyzed enantioselective Povarov reaction to access tetrahydroquinolines. Nat. Protoc. 9, 1860-1866 (2014).

43. Mo, J., Yang, R., Chen, X., Tiwari, B. \& Chi, Y. R. Direct $\alpha$-functionalization of simple aldehydes via oxidative N-heterocyclic carbene catalysis. Org. Lett. 15, 50-53 (2013).

44. El Amrani, M. et al. Protein kinase and HDAC inhibitors from the endophytic fungus Epicoccum nigrum. J. Nat. Prod. 77, 49-56 (2014).

45. Corbett, J. W. et al. Inhibition of clinically relevant mutant variants of HIV-1 by quinazolinone non-nucleoside reverse transcriptase inhibitors. J. Med. Chem. 43, 2019-2030 (2000).

46. Namitharan, K. et al. Metal and carbene organocatalytic relay activation of alkynes for stereoselective reactions. Nat. Commun. 5, 4982 (2014).

47. Zheng, P. et al. Oxidative N-heterocyclic carbene-catalyzed $\gamma$-carbon addition of enals to imines: mechanistic studies and access to antimicrobial compounds. Chem. Eur. J. 21, 9984-9987 (2015).

48. Wang, X. et al. Synthesis and bioactivity evaluation of novel aryl imines containing a 3-aminoethyl-2-[( $p$-trifluoromethoxy)anilino $]-4(3 \mathrm{H})$ quinazolinone moiety. J. Agric. Food Chem. 61, 9575-9582 (2013).

\section{Acknowledgements}

We acknowledge support by Singapore National Research Foundation (NRF), Ministry of Education, Singapore Economic Development Board (EDB), GlaxoSmithKline (GSK) Nanyang Technological University (NTU) and City University of Hong Kong (CityU); and China's National Key Program for Basic Research (No. 2010CB 126105), Thousand Talent Plan, National Natural Science Foundation of China (nos. 21132003 and 21472028), the Returned Overseas Student Science and Technology Activity Program of Guizhou Province, The Guizhou Science and Technology Department's Key Program and Guizhou University. We thank Dr Y.-X. Li and R. Ganguly (NTU) for assistance with X-ray structure analysis.

\section{Author contributions}

X.-K.C. proposed the $[4+2]$ annulation reactions and performed most of the experiments; H.W., C.Y.O., P.Z., W.L. and H.G. conducted part of the synthesis experiments and the bioactivity studies; K.D. and H.H. carried out computational studies of the reaction mechanism; S.Y. and B.-A.S. directed the bioactivity studies. Y.R.C. conceptualized and directed the project and drafted the manuscript with the assistance from all co-authors. All authors contributed to discussions. 


\section{Additional information}

Supplementary Information accompanies this paper at http://www.nature.com/ naturecommunications

Competing interests: The authors declare no competing financial interests.

Reprints and permission information is available online at http://npg.nature.com/ reprintsandpermissions/

How to cite this article: Chen, $\mathrm{X}$. et al. A reaction mode of carbene-catalysed aryl aldehyde activation and induced phenol $\mathrm{OH}$ functionalization. Nat. Commun. 8, 15598 doi: 10.1038/ncomms15598 (2017).
Publisher's note: Springer Nature remains neutral with regard to jurisdictional claims in published maps and institutional affiliations.

(c) (i) This work is licensed under a Creative Commons Attribution 4.0 International License. The images or other third party material in this article are included in the article's Creative Commons license, unless indicated otherwise in the credit line; if the material is not included under the Creative Commons license, users will need to obtain permission from the license holder to reproduce the material. To view a copy of this license, visit http://creativecommons.org/licenses/by/4.0/

(C) The Author(s) 2017 